\title{
NMDA receptor subunit composition determines beta-amyloid-induced neurodegeneration and synaptic loss
}

\author{
C Tackenberg ${ }^{\star, 1}$, S Grinschgl ${ }^{1}$, A Trutzel ${ }^{1}$, AC Santuccione ${ }^{1}$, MC Frey ${ }^{1}$, U Konietzko ${ }^{1}$, J Grimm ${ }^{2}$, R Brandt ${ }^{3}$ and RM Nitsch ${ }^{1}$
}

Aggregates of amyloid-beta (A $\beta$ ) and tau are hallmarks of Alzheimer's disease (AD) leading to neurodegeneration and synaptic loss. While increasing evidence suggests that inhibition of $\mathrm{N}$-methyl-D-aspartate receptors (NMDARs) may mitigate certain aspects of AD neuropathology, the precise role of different NMDAR subtypes for $A \beta$ - and tau-mediated toxicity remains to be elucidated. Using mouse organotypic hippocampal slice cultures from $\operatorname{arc} A \beta$ transgenic mice combined with Sindbis virusmediated expression of human wild-type tau protein (hTau), we show that A $\beta$ caused dendritic spine loss independently of tau. However, the presence of $\mathrm{hTau}$ was required for $\mathrm{A} \beta$-induced cell death accompanied by increased hTau phosphorylation. Inhibition of NR2B-containing NMDARs abolished A $\beta$-induced hTau phosphorylation and toxicity by preventing GSK-3 $\beta$ activation but did not affect dendritic spine loss. Inversely, NR2A-containing NMDAR inhibition as well as NR2A-subunit knockout diminished dendritic spine loss but not the $A \beta$ effect on hTau. Activation of extrasynaptic NMDARs in primary neurons caused degeneration of hTau-expressing neurons, which could be prevented by NR2B-NMDAR inhibition but not by NR2A knockout. Furthermore, caspase- 3 activity was increased in arcA $\beta$ transgenic cultures. Activity was reduced by NR2A knockout but not by NR2B inhibition. Accordingly, caspase-3 inhibition abolished spine loss but not hTau-dependent toxicity in arcA $\beta$ transgenic slice cultures. Our data show that $A \beta$ induces dendritic spine loss via a pathway involving NR2A-containing NMDARs and active caspase-3 whereas activation of eSyn NR2B-containing NMDARs is required for hTau-dependent neurodegeneration, independent of caspase-3.

Cell Death and Disease (2013) 4, e608; doi:10.1038/cddis.2013.129; published online 25 April 2013

Subject Category: Neuroscience

Aggregates of amyloid-beta $(\mathrm{A} \beta)$ and tau are hallmarks of Alzheimer's disease (AD). It has been shown that tau may mediate critical pathological effects downstream of $A \beta .^{1-5}$ Nevertheless, how extracellular $\mathrm{A} \beta$ and intracellular tau pathology is functionally connected remains unclear.

Soluble $\mathrm{A} \beta$ can bind to or near NMDARs indicating NMDARs as potential targets of $\mathrm{A} \beta .^{6-8}$ Preventing synaptic targeting of $\mathrm{A} \beta^{9}$ or blocking NMDAR activation ${ }^{2,10}$ can abolish $\mathrm{A} \beta$-induced dendritic spine loss and tau-dependent toxicity. NMDARs can be categorized by subunit composition and by localization. It has been shown that synaptic and extrasynaptic (eSyn) NMDAR signaling is gated by different coagonists, ${ }^{11}$ has opposite effects on cell survival and that differentially located NMDARs are coupled to different intracellular cascades. $^{12,13}$ Some studies showed NR2Asubunit-containing NMDARs incorporated into the synapse whereas NR2B-containing NMDARs were found predominantly at extrasynaptic locations. ${ }^{11,14-16}$ However, others reported NR2A- and NR2B-containing NMDARs at both locations. ${ }^{17,18}$ Contrasting data exist on the effect of $A \beta$ on different NMDAR types. Oligomeric $\mathrm{A} \beta$ induced neuronal dysfunctions by activation of NR2B-containing NMDARs. ${ }^{19}$
Further, $\mathrm{A} \beta$ caused loss of synaptic proteins PSD-95 and synaptophysin by NR2B-containing NMDAR activation accompanied by the suppression of NR2A-containing NMDAR function. ${ }^{20}$ In contrast, $\mathrm{A} \beta$ particularly activated NR2A-containing NMDARs after heterologous expression in Xenopus oocytes. ${ }^{21}$

Here, we show that NR2A- and NR2B-subunit containing NMDARs differentially mediate $A \beta$-induced tau phosphorylation, cell death and dendritic spine loss. The presence of human wild-type tau protein (hTau) was essential for $\mathrm{A} \beta$-induced neurodegeneration. Neuronal death required activation of extrasynaptic NR2B-containing NMDARs followed by increased hTau phosphorylation while dendritic spine loss was mediated by NR2A-containing NMDARs signaling and active caspase-3, independent of tau.

\section{Results}

A $\beta$ induces hTau-dependent neurotoxicity and tau-independent dendritic spine loss. We determined the role of $\mathrm{A} \beta$ and tau for neuronal cell death and dendritic spine loss using organotypic hippocampal slice cultures from

${ }^{1}$ Division of Psychiatry Research, University of Zurich, August-Forel-Strasse 1, 8008 Zurich, Switzerland; ${ }^{2}$ Neurimmune Holding AG, Wagistrasse 13,8952 Schlieren, Switzerland and ${ }^{3}$ Department of Neurobiology, University of Osnabrück, Barbarastrasse 11, 49076 Osnabrück, Germany

${ }^{*}$ Corresponding author: C Tackenberg, Division of Psychiatry Research, University of Zurich, August-Forel-Strasse 1, 8008 Zurich, Switzerland. Tel: +41 446348888 ; Fax: +41 44634 8879; E-mail: christian.tackenberg@bli.uzh.ch

Keywords: amyloid-beta; $A \beta$; tau; dendritic spine; neurodegeneration; NMDA receptor

Abbreviations: APP, amyloid precursor protein; A $\beta$, amyloid $\beta$-peptide; AD, Alzheimer's disease; EGFP, enhanced green fluorescent protein; hTau, human wild-type tau protein; mTau, endogenous murine tau; NMDAR, $N$-methyl-D-aspartate receptor

Received 13.12.12; revised 13.3.13; accepted 18.3.13; Edited by A Verkhratsky 
7-day-old $\operatorname{arcA} \beta \operatorname{tg}$ mice combined with virus-mediated expression of enhanced green fluorescent protein (EGFP)coupled 441 residue isoform of hTau or EGFP alone using neurovirulent Sindbis virus. By Live/Dead assays, the proportion of living and dead cells in slice cultures was determined. After 16 days in vitro (DIV), dead cell staining increased significantly after hTau overexpression in $\operatorname{arcA} \beta$ tg cultures compared with non-tg cultures, which was prevented in the presence of $1 \mu \mathrm{g} / \mathrm{ml}$ of the $N$-terminal $\mathrm{A} \beta$ antibody A $\beta$ antibody 6E10 (Figure 1a). In agreement, hTau overexpression caused cytotoxicity in $\operatorname{arc} A \beta$ transgenic slice cultures compared with non-tg controls (Figure $1 \mathrm{~b}$ ) as analyzed with Cytotox-Glo assay. Toxicity was completely abolished in the presence of $1 \mu \mathrm{g} / \mathrm{ml}$ of $6 \mathrm{E} 10$ or mid-domain $\mathrm{A} \beta$ antibody, which does not detect cell-surface amyloid precursor protein (APP) but not with control antibody suggesting that hTau-dependent toxicity in $\operatorname{arcA} \beta$ cultures was induced by $\mathrm{A} \beta$ rather than by APP or any other product of APP processing.

To determine the effect of $\mathrm{A} \beta$ and tau on dendritic spines, high-resolution imaging of dendritic segments and spines was performed in slice cultures. A strong reduction of dendritic spine numbers by $40-50 \%$ was observed in CA1 and CA3 neurons from $\operatorname{arcA} \beta$ cultures compared with non-tg cultures. Spine loss was completely abolished after treatment with $6 \mathrm{E} 10$ or mid-domain $\mathrm{A} \beta$ antibody but not by control antibody (Figures 1c and d). Antibody treatment reduced $\mathrm{A} \beta$ ELISA signals (Figure 1e) indicating that the removal of $\mathrm{A} \beta$ from culture medium is sufficient to prevent hTaudependent toxicity. The effects of $\mathrm{A} \beta$ in cultures from transgenic mice could be confirmed by treatment of wild-type (wt) cultures with recombinant preparations of $\mathrm{A} \beta 42^{22}$ (Supplementary Figure S1).

We showed previously that overexpression of wt or mutant $\mathrm{hTau}$ in the presence or absence of $\mathrm{A} \beta$ did not affect dendritic spine density or morphology. ${ }^{2,23}$ Nevertheless, it could not be excluded that endogenous mouse tau mediated $A \beta$-induced dendritic spine loss. To determine a potential involvement of endogenous tau, organotypic slice cultures were prepared from tau $^{-I-}$ mice and treated with $1 \mu \mathrm{M}$ recombinant $\mathrm{A} \beta 42$, which caused strong reduction in spine density compared with untreated tau $^{-1-}$ cultures (Figures $1 \mathrm{f}$ and g). Tau depletion itself did not affect dendritic spine number. The degree of spine loss in tau $^{-1-}$ cultures after $A \beta$ treatment was similar to that observed in cultures expressing endogenous tau, indicating that endogenous tau is not involved in $\mathrm{A} \beta$-induced spine loss in our model.

\footnotetext{
NR2B-containing NMDARs mediate $A \beta$-induced hTaudependent toxicity whereas NR2A-containing NMDARs are involved in dendritic spine loss. We determined the role of NR2A- and NR2B-containing NMDARs for $\mathrm{A} \beta$-induced neuronal cell death and dendritic spine loss. Although potent NR2B antagonists, for example, Ifenprodil, exist, selectivity of NR2A antagonists is rather low. One of the most selective NR2A antagonists, PEAQX, has been shown to have a 13-130-fold preference for NR1/NR2A over NR1/NR2B receptors. ${ }^{24-26}$ However, to avoid any bias due to nonspecific binding of PEAQX, we supported this data by using cultures from NR2A-knockout (NR2AKO) mice in addition. Ifenprodil and PEAQX concentrations were
}

chosen according to previous reports demonstrating highest degree of specificity. ${ }^{19,26}$

We found increased toxicity and AT8 phosphorylation of hTau in cultures from NR2AKO $\times \operatorname{arcA} \beta \operatorname{tg}$ mice compared with NR2AKO control cultures (Figures $2 a$ and b). In agreement, treatment with NR2A antagonist PEAQX did not prevent toxicity and AT8 phosphorylation of hTau in $\operatorname{arcA} \beta \operatorname{tg}$ cultures (Figures 2c and d). In contrast, treatment with NR2B antagonist Ifenprodil abolished hTau-dependent toxicity (Figure 2e) and reduced AT8 phosphorylation of hTau in $\operatorname{arcA} \beta \operatorname{tg}$ slices (Figure 2f). We further show that activity of GSK-3 $\beta$, one of the major tau kinases, was increased in $\operatorname{arcA} \beta$ tg slices. Activity could be reduced by Ifenprodil treatment to control levels (Supplementary Figures S2a and b). In addition, slice cultures were treated with $20 \mathrm{mM}$ lithium ( $\mathrm{LiCl}$ ), known to block GSK-3 $\beta$ activity, ${ }^{27,28}$ which prevented hTau toxicity in $\operatorname{arcA} \beta$ tg slices (Supplementary Figure S2c). This suggests that GSK-3 $\beta$ causes hTau phosphorylation and toxicity downstream of NR2B-containing NMDARs.

Opposite effects with respect to NMDA receptor subunit composition were observed on dendritic spine density as both NR2AKO and PEAQX treatment prevented $\mathrm{A} \beta$-induced spine loss while Ifenprodil did not (Figures $2 \mathrm{~g}-\mathrm{l}$ ). We confirmed the Ifenprodil data by using a further NR2B inhibitor, Ro 25-6981, which gave identical results (Supplementary Figure S3). Note that NR2A-NMDAR inhibition with PEAQX slightly decreased spine density in control cultures. Our data suggest that $\mathrm{A} \beta$ induces tau-dependent cell death and tau-independent loss of dendritic spines by different pathways involving NR2B- or NR2A-containing NMDAR-mediated signaling, respectively.

Activation of extrasynaptic NMDARs induces hTaudependent toxicity but no spine loss. We aimed to determine the role of synaptic and extrasynaptic NMDARs for $\mathrm{A} \beta$-induced $\mathrm{hTau}$ toxicity using a protocol that has been shown to selectively activate synaptic versus extrasynaptic NMDARs. ${ }^{12,29,30}$ In primary neuronal cultures from non-tg mice expressing only EGFP, we observed no toxicity after synaptic or extrasynaptic NMDAR activation (Figure 3a upper row, Figure 3c). This is in agreement with a study showing that the use of NMDA for up to $180 \mathrm{~min}$ to activate extrasynaptic NMDARs does not induce morphological changes to the neuronal network or increase LDH release from neuronal cultures. ${ }^{30}$ However, upon hTau expression, the activation of extrasynaptic NMDARs caused a significant increase in toxicity as evidenced by fragmented or beaded neurites and ballooned neurons (Figure 3a lower row, Figure 3c). A ballooned phenotype was already found to be a characteristic for cell death caused by abnormally phosphorylated tau in culture ${ }^{2,23}$ and is a histopathological feature of several neurodegenerative diseases, including Pick's disease and AD. ${ }^{31}$ Immunostaining against $\beta$ III tubulin showed no degeneration of non-infected neurons after extrasynaptic activation in primary neuronal cultures (Figure 3b, arrows) confirming that extrasynaptic NMDAR activation causes selective toxicity only in EGFPhTau-expressing neurons. Increased phosphorylation of ERK kinase after synaptic but not after extrasynaptic activation confirms the selective activation of the respective NMDARs in our protocol. $^{29,30}$ Extrasynaptic activation also induced hTau- 

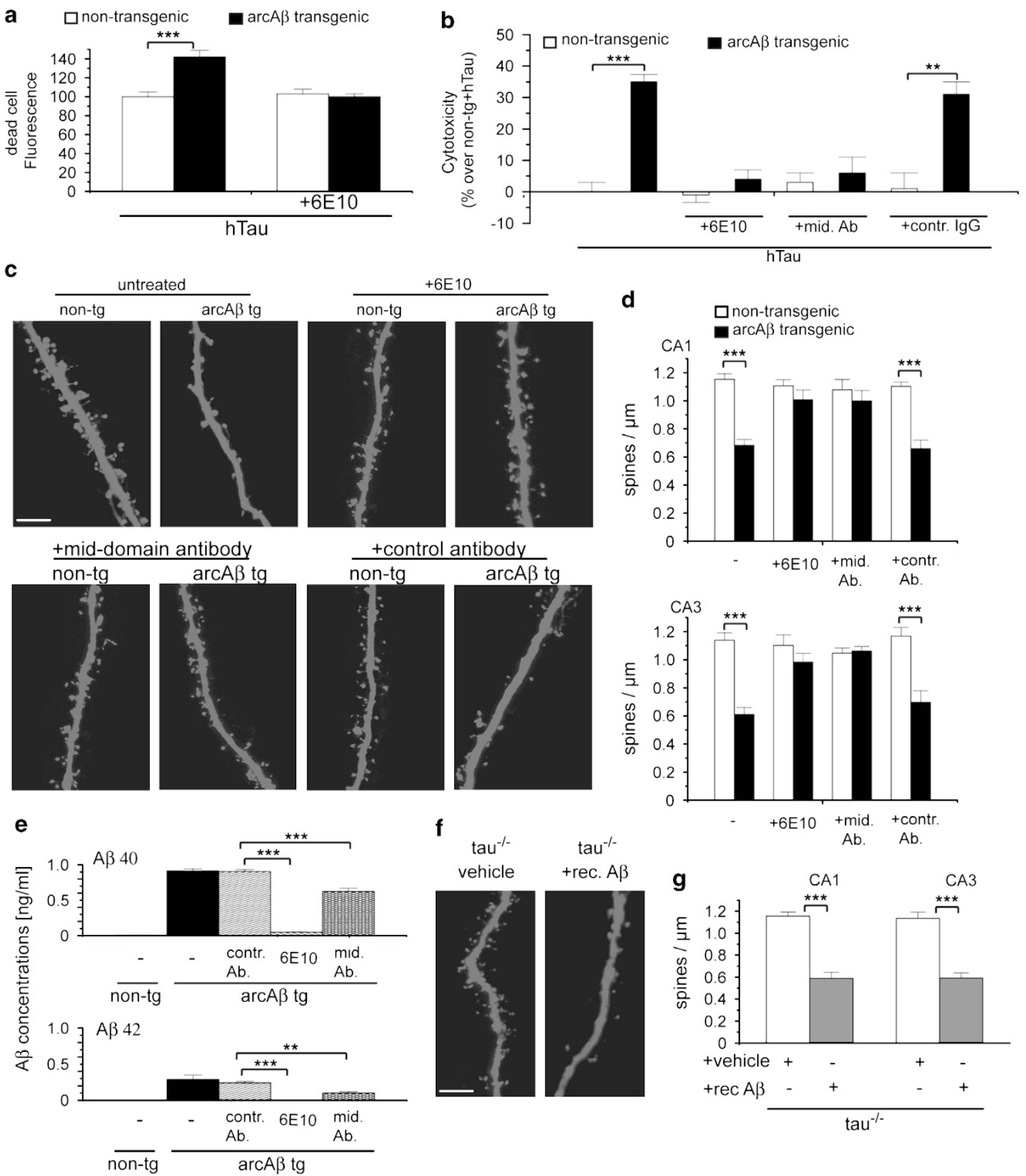

f $\mathrm{tau}^{-1-} \quad \mathrm{tau}^{-1-}$ vehicle $\quad+$ rec. $A \beta$
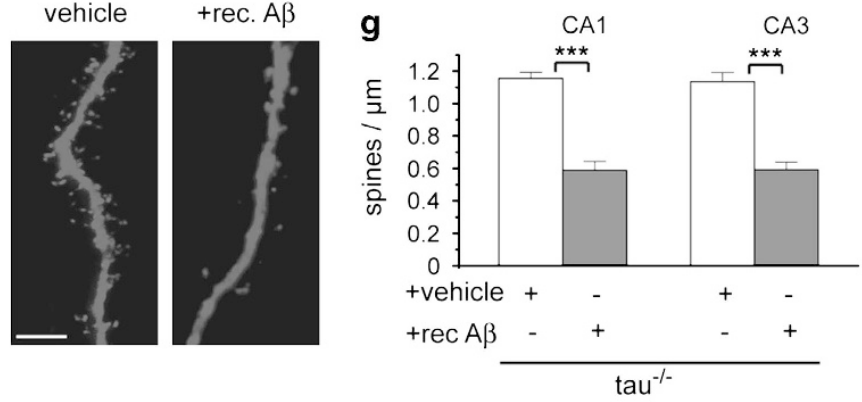

Figure $1 \mathrm{~A} \beta$ induces hTau-dependent neurotoxicity and tau-independent spine loss. (a) Quantification of dead cell fluorescence intensities of hTau-expressing hippocampal slice cultures from $\operatorname{arcA} \beta \operatorname{tg}$ and non-tg mice treated with $\mathrm{A} \beta$ antibody $6 \mathrm{E} 10$ determined by Live/Dead cell viability/cytotoxicity assay. (b) Cytotoxicity of hTau in $\operatorname{arcA} \beta$ tg and non-tg control slice cultures treated with $1 \mu \mathrm{g} / \mathrm{ml}$ of $\mathrm{A} \beta$ antibody $6 \mathrm{E} 10$, a mid-domain $\mathrm{A} \beta$ antibody or control antibody measured by Cytotox-Glo assay. (c) Confocal images of apical dendritic segments from CA1 neurons of $\operatorname{arcA} \beta \operatorname{tg}$ and non-tg slices in the presence or absence of $A \beta$ antibody $6 E 10$, mid-domain $A \beta$ antibody or control antibody. (d) Quantification of spine density in cultures from $\operatorname{arc} A \beta \operatorname{tg}$ and non-tg mice. (e) Quantitative bar graphs representing mean values of the amount of $A \beta 40$ and $\mathrm{A} \beta 42$ peptides in medium of $\operatorname{arc} A \beta$ hippocampal slice cultures after treatment with respective $\mathrm{A} \beta$ antibodies as determined by ELISA. (f) Representative images of apical

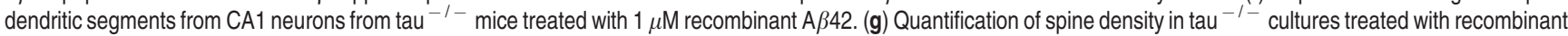
$\mathrm{A} \beta$ 42. rec. $\mathrm{A} \beta$, recombinant $\mathrm{A} \beta 42$; mid. Ab, mid-domain $\mathrm{A} \beta$ antibody; contr. Ab, control antibody; mean \pm S.E.M.; ${ }^{* \star} P<0.01$ and ${ }^{* \star *} P<0.001$; Mann-Whitney-U-test; $n=9-13, n=4$ (e) scale bar: $5 \mu \mathrm{m}$

dependent toxicity and increased AT8 phosphorylation in organotypic hippocampal slices (Figures $3 e$ and f). However extrasynaptic activation did not affect dendritic spine density in slice cultures (Figures $3 \mathrm{~g}$ and $\mathrm{h}$ ). These data suggests a major role of extrasynaptic NMDARs for tau-dependent cell death.
Antagonizing NR2B-containing NMDARs abolishes hTau-dependent toxicity after extrasynaptic NMDAR activation. We showed that hTau-dependent toxicity in $\operatorname{arcA} \beta \operatorname{tg}$ cultures was mediated via NR2B-dependent signaling (Figures $2 a$ and $b$ ) and that activation of 
extrasynaptic NMDARs could mimic the effect of $A \beta$ to induce hTau-dependent toxicity (Figures $3 a-c$ ). We next aimed to determine whether extrasynaptically located
NR2B-containing NMDARs mediated the induction of hTaudependent toxicity. Activation of extrasynaptic NMDARs in the presence of Ifenprodil did not induce hTau-dependent a

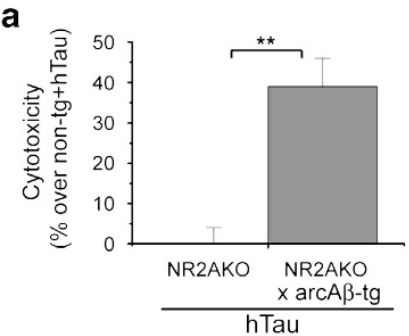

C

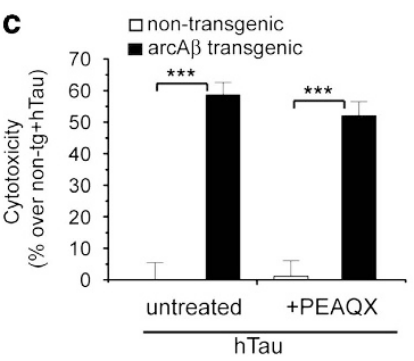

e

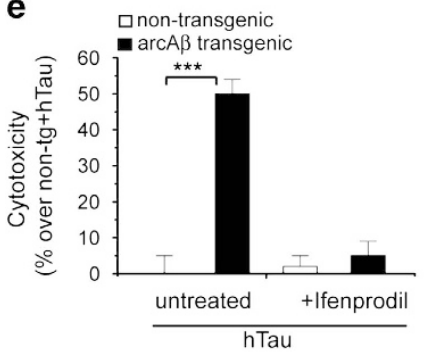

g

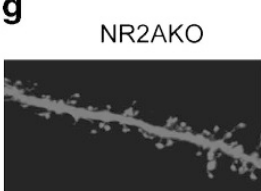

i

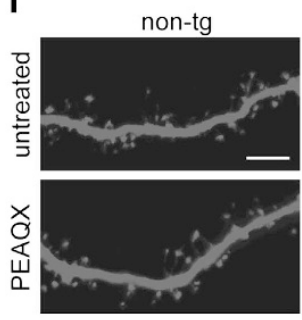

k

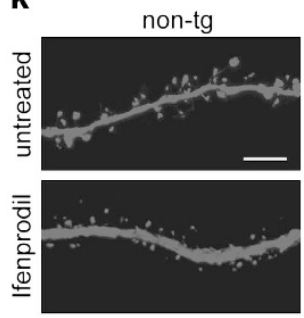

b
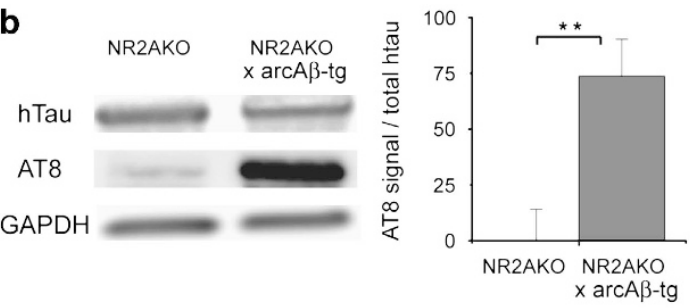

d
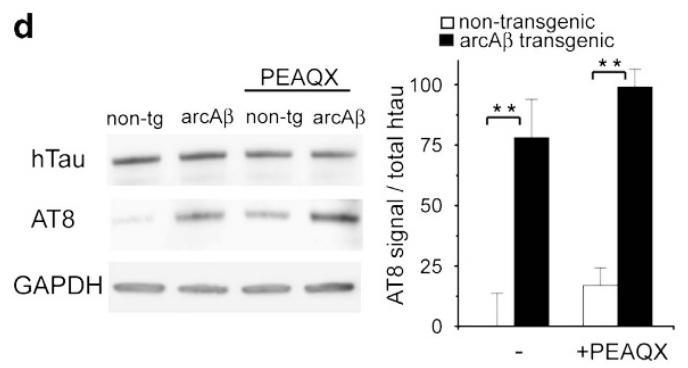

f
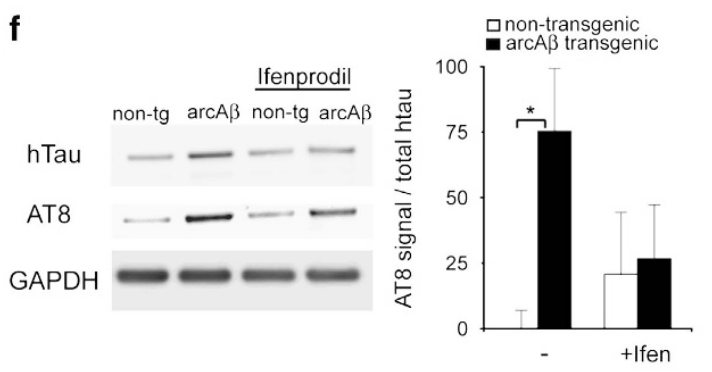

h

h $\square$ NR2AKO $\square$ NR2AKO $x$ aICAB-tg
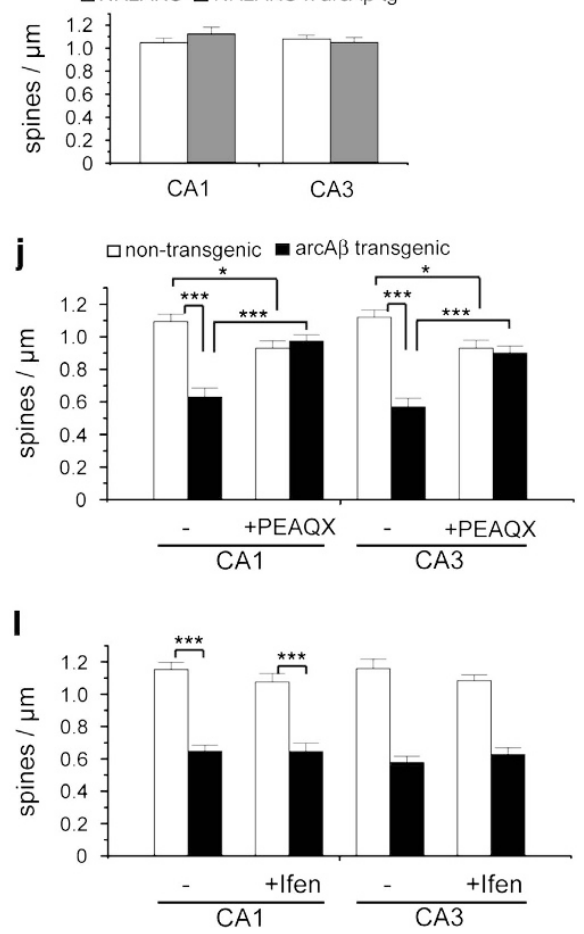
toxicity (Figures 4a, c and d), while strong degeneration of hTau-expressing neurons was observed after extrasynaptic activation in NR2AKO neurons (Figures $4 \mathrm{~b}$ and e). This suggests that extrasynaptically localized NR2B- but not NR2A-containing NMDARs mediated hTau-dependent toxicity. The expression of both NR2A- and NR2B-subunits (GRIN2A and GRIN2B) in primary neurons was verified by RT-PCR (Grinschgl et al., unpublished observations).

A $\beta$-induced caspase- 3 activity is required for dendritic spine loss. Caspase- 3 has been shown to be activated by $\mathrm{A} \beta^{20}$ and to trigger early synaptic dysfunctions in $\mathrm{APP}_{\text {Swe }}$ tg mice. $^{32}$ Accordingly, increased proteolytic cleavage of procaspase-3 into a 17-kDa active caspase-3 fragment was observed in $\operatorname{arcA} \beta$ transgenic slice cultures. Treatment with NR2B antagonist Ifenprodil did not prevent caspase-3 activation whereas increased caspase- 3 activation was not observed after NR2A-subunit knockout (Figures 5a and b). To verify the role of active caspase- 3 in mediating the effects of $\mathrm{A} \beta$, slices were treated with $10 \mu \mathrm{M}$ of caspase- 3 inhibitor Z-DEVD-FMK. Treatment did not prevent hTau-dependent toxicity in $\operatorname{arcA} \beta \operatorname{tg}$ cultures (Figure $5 \mathrm{c}$ ) but abolished $\mathrm{A} \beta$-induced spine loss (Figures $5 \mathrm{~d}$ and $\mathrm{e}$ ). Thus, active caspase-3 is involved in NR2A-dependent dendritic spine loss, while it is not required for hTau-dependent toxicity induced by $\mathrm{A} \beta$ in our model.

\section{Discussion}

The results of this study establish the differential involvement of synaptic and extrasynaptic NR2A- and NR2B-subunitcontaining NMDARs in pathways coupling $A \beta$ to loss of dendritic spines and hTau-dependent neurodegeneration. Using selective pharmacological inhibition combined with knockout techniques, we show that $\mathrm{A} \beta$ induced hTaudependent toxicity accompanied by increased hTau phosphorylation via activation of extrasynaptic NR2B-containing NMDARs. In contrast, loss of dendritic spines was mediated by NR2A-containing NMDAR signaling. Importantly, A $\beta$ also induced spine loss in cultures prepared from tau-deficient mice suggesting that loss of postsynaptic spines is not dependent on endogenous mouse tau. In agreement with the missing involvement of endogenous tau for spine loss, overexpression of wt or mutant hTau did also not affect spine number or shape as previously shown. ${ }^{2,23}$ However, hTau overexpression in the presence of either recombinant or transgenically expressed $\mathrm{A} \beta$ caused cell death with hTau being abnormally phosphorylated at the AT8 epitope. Interestingly, $\mathrm{A} \beta$ did not induce detectable toxicity in the presence of endogenous murine tau (mTau). We did not find any effect of $\mathrm{A} \beta$ on AT8 phosphorylation of $\mathrm{mTau}$ (Supplementary Figure S4), suggesting that hTau may be a better substrate for hyperphosphorylation and induction of cell death than mTau. In agreement, lentiviral expression of hTau accelerated the neurotoxic effect of $\mathrm{A} \beta$ dimers compared with endogenous tau in primary neurons. ${ }^{33}$

Increased activation or expression of several tau kinases, for example GSK-3 $\beta,{ }^{34}$ as well as reduced activity of tau phosphatases ${ }^{35}$ has been reported in $A D$, and toxicity of phosphorylated tau has been shown in various studies. $2,23,33,36$ Recently, a longitudinal study of 286 participants revealed that $\mathrm{A} \beta$-associated brain volume loss occurs only in the presence of phosphorylated tau in the human brain. ${ }^{37}$

The mechanisms by which tau causes degeneration of neurons are discussed controversially. Four independently created tau-knockout lines show largely normal behavior, ${ }^{38-41}$ indicating that loss of tau function does not cause neurodegeneration. Accumulating evidence points to the possibility that physiological functions of tau may be involved in neuronal excitotoxicity $^{3,4,42}$ or axonal transport dysfunction ${ }^{43}$ in APP transgenic mice and that tau interactions other than microtubule binding may also be involved. ${ }^{44}$ Furthermore, several in vitro and in vivo studies support abnormal gain of toxic function for tau caused by hyperphosphorylation. 2,23,33,36,45 Together, both phosphorylation-independent physiological tau functions as well as hyperphosphorylation-induced gain of toxic function may not be mutually exclusive and jointly contribute to neuronal dysfunction in disease.

NMDARs are potential targets of $A \beta$ as soluble $A \beta$ can bind to or near NMDARs. ${ }^{6,7}$ Some studies showed NR2A-subunitcontaining NMDARs incorporated into the synapse whereas NR2B-containing NMDARs were found predominantly at extrasynaptic locations. ${ }^{14-16}$ However, others reported NR2A- and NR2B-containing NMDARs at both locations. ${ }^{17,18}$ Signaling via NR2A- or NR2B-containing NMDARs causes different or even opposing effects. ${ }^{46-49}$ The same applies for synaptic or extrasynaptic NMDAR activity. ${ }^{12,29,30,50-52}$ Thus, specific NMDAR function may depend on both subunit composition and spatial distribution suggesting that NR2Aand NR2B-containing NMDARs at both locations are each coupled to different cascades.

We analyzed the involvement of different NMDAR subtypes and locations for spine loss and tau toxicity in $\operatorname{arcA} \beta \operatorname{tg}$ cultures. Knockout and inhibition of NR2A-containing NMDARs but not of NR2B-containing NMDARs prevented spine loss in $\operatorname{arc} \mathrm{A} \beta$ cultures. In agreement, $\mathrm{A} \beta$ has been shown to influence NR2A-containing NMDARs although the

Figure 2 NR2B-containing NMDAR inhibition prevents A $\beta$-induced hTau-dependent toxicity whereas NR2A knockout or inhibition abolishes dendritic spine loss. (a) Cytotoxicity of $h$ Tau in NR2AKO $\times$ arcA $\beta$ tg and NR2AKO cultures measured by Cytotox-Glo assay. (b) Western blot showing AT8 phosphorylation of $h$ Tau in NR2AKO $\times \operatorname{arcA} \beta$ tg and NR2AKO cultures. (c) Cytotoxicity of hTau in $\operatorname{arcA} \beta$ tg and non-tg control cultures treated with $50 \mathrm{nM}$ PEAQX. (d) Western blot showing expression of hTau and phosphorylation at AT8 epitope after PEAQX treatment. (e) Cytotoxicity of hTau in $\operatorname{arcA} \beta$ tg and non-tg control cultures treated with $3 \mu \mathrm{M}$ Ifenprodil. (f) Western blot showing phosphorylation of hTau at AT8 epitope after Ifenprodil treatment. $(\mathbf{g})$ Representative confocal images of apical dendritic segments from NR2AKO and NR2AKO $\times$ $\operatorname{arcA} \beta$ tg cultures. (h) Spine density in NR2AKO and NR2AKO $\times \operatorname{arcA} \beta \operatorname{tg}$ cultures. (i) Apical dendritic segments from CA1 neurons of $\operatorname{arcA} \beta$ tg and non-tg slices in the presence or absence of $50 \mathrm{nM}$ PEAQX. (j) Quantification of spine density after treatment with PEAQX. (k) Apical dendritic segments from CA1 neurons of arcA $\beta$ tg and non-tg slices in the presence or absence of $3 \mu \mathrm{M}$ Ifenprodil. (I) Quantification of spine density after treatment with Ifenprodil. Ifen, Ifenprodil; NR2AKO, NR2A-containing NMDAR knockout; values are shown as mean \pm S.E.M. with ${ }^{\star} P<0.05,{ }^{\star *} P<0.01$ and ${ }^{* \star *} P<0.001$; Mann-Whitney-U-test; $n=6-8$ (a, c,e), $n=5$ (b), $n=4$ (d), $n=6$ (f), $n=10-13$ (h, j, I); scale bar: $5 \mu \mathrm{m}$ 
results are controversial: in Xenopus oocytes, $\mathrm{A} \beta$ directly activated NR2A-containing NMDARs ${ }^{21}$ whereas $\mathrm{A} \beta$ blocked NR2A-containing NMDARs in primary rat neurons leading to loss of PSD-95 and synaptophysin signals. ${ }^{20}$
We now show for the first time that $A \beta$-induced hTau phosphorylation and toxicity was mediated by NR2B- but not NR2A-containing NMDAR-dependent signaling and involved NR2B-dependent activation of tau kinase GSK-3 $\beta$.
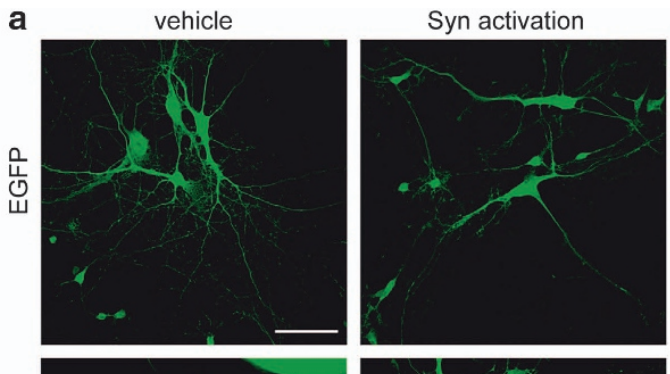

eSyn activation
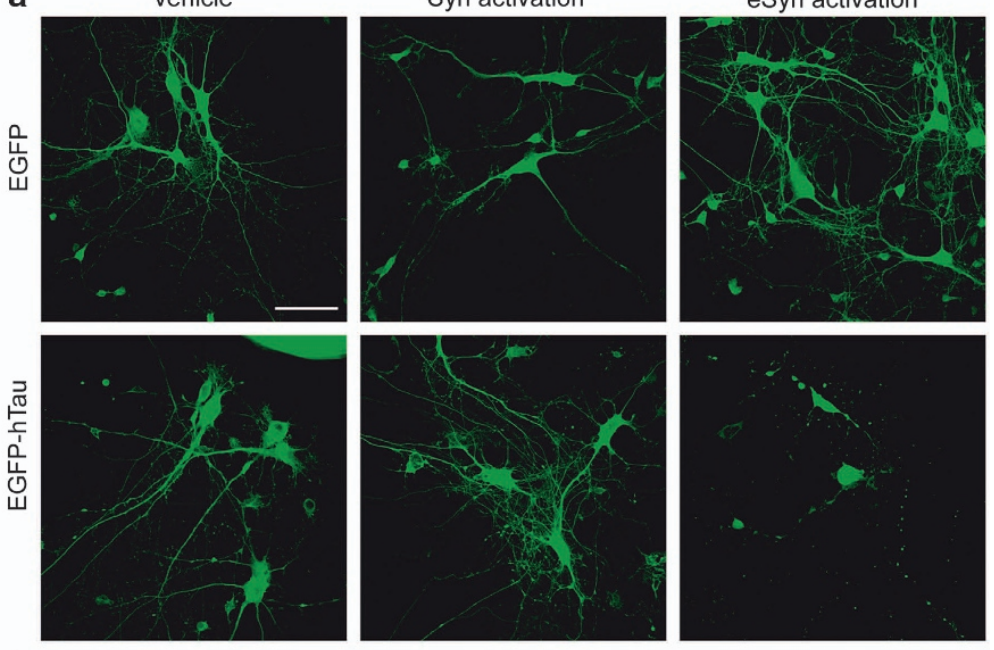

b

$$
\text { eSyn activation }
$$

eSyn activation

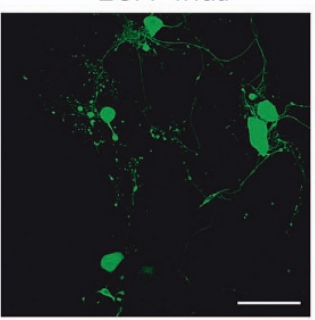

BIII tubulin
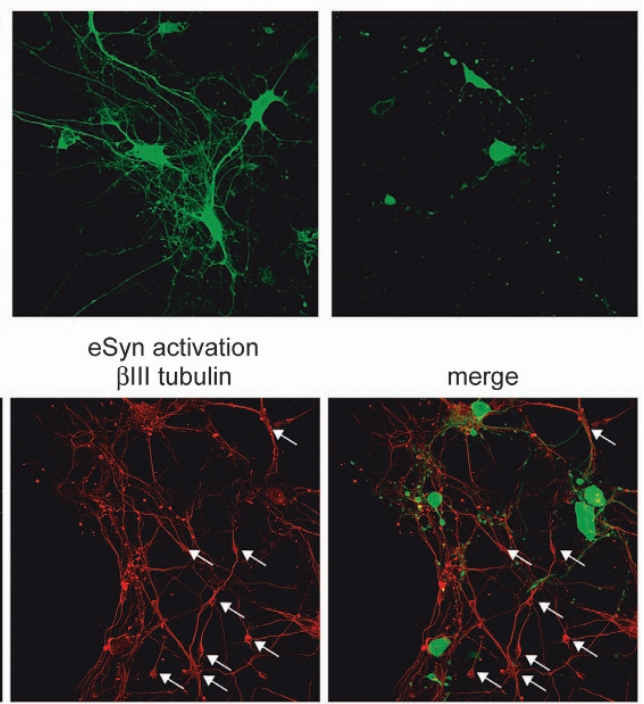

merge

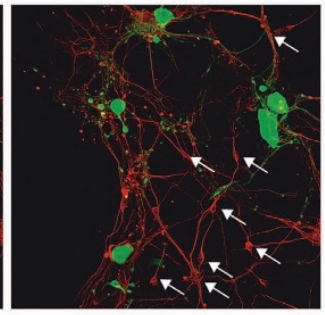

C $\square$ vehicle $\square$ Syn act. $\square$ eSyn act.

d vehicle

Syn

eSyn
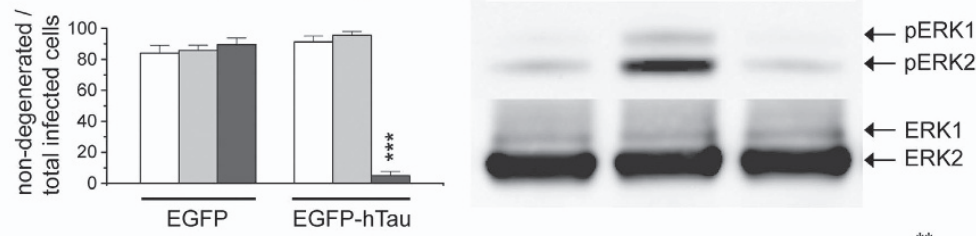

e
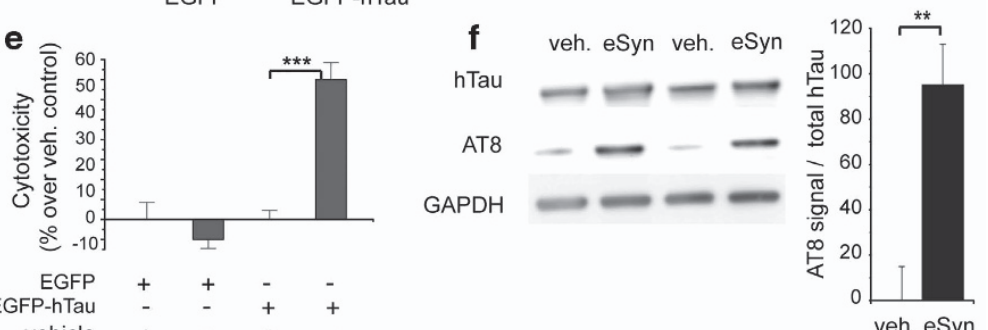

vehicle

eSyn act.

g
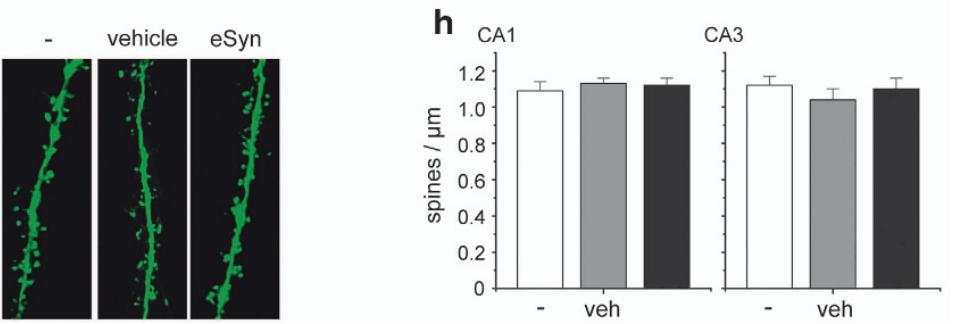
An involvement of NR2B-containing NMDARs for tau toxicity was also reported previously ${ }^{53}$ where Ifenprodil blocked toxicity after tau overexpression in dissociated primary neurons. However, no increased tau phosphorylation was found and tau toxicity was analyzed in the absence of $A \beta$ implying different mechanisms of toxicity in both studies.

In agreement with our data, soluble $\mathrm{A} \beta$ oligomers have been shown to excessively activate extrasynaptic NR2Bcontaining NMDARs in acute slice cultures, ${ }^{19}$ and activation of NR2B-containing NMDARs by $\mathrm{A} \beta$ in primary neurons resulted in a loss of synaptophysin- and PSD-95 signals. ${ }^{20}$ We show that $A \beta$ increased proteolytic caspase- 3 activation via NR2Abut not NR2B-mediated signaling. Further, pharmacological caspase-3 inhibition abolished $\mathrm{A} \beta$-induced dendritic spine loss but not hTau-dependent toxicity indicating that $\mathrm{A} \beta$-induced synaptic loss is mediated by NR2A signaling followed by caspase-3 activation. Caspase-3 activation has been shown to be required for long-term depression (LTD) ${ }^{54}$ and is also involved in A $\beta$-induced loss of PSD-95 and synaptophysin signals ${ }^{20}$ and inhibition of LTP. ${ }^{55}$ We and others have shown that the calcium-dependent phosphatase calcineurin, a key enzyme in LTD, can trigger $\mathrm{A} \beta$-induced changes and loss of dendritic spines ${ }^{2,10,56,57}$ via an LTD-like cascade. Calcineurin can be activated by caspase- 3 in dendritic spines ${ }^{32}$ thus linking NR2A-mediated activation of caspase-3 to dendritic spine loss.

In conclusion, our data uncover two independent pathways for neuronal and synaptic loss, both triggered by $\mathrm{A} \beta$, which already differ in their requirement for distinct types of NMDARs. This may explain the difficulty and the big challenge to find appropriate drug targets downstream of $A \beta$ in order to prevent synaptic loss and neuronal cell death in AD.

\section{Materials and Methods}

Animals. ArcA $\beta$ mice and NR2A-NMDA receptor-knockout mice were obtained as described. ${ }^{58,59}$ Tau-deficient B6.129-Mapt ${ }^{\text {tm1 Hnd/J }}$ mice ${ }^{39}$ were purchased from Jackson Laboratories (Bar Harbor, ME, USA). All animal experiments were performed in accordance with the guidelines of the Swiss veterinary cantonal office.

\section{Organotypic hippocampal slice culture and viral infection. Organotypic hippocampal slice cultures were prepared and cultured as previously described. ${ }^{2}$ On DIV 12, slice cultures were infected with Sindbis virus using the droplet method. For assessment of dendritic spine density, cultures were infected with Sindbis virus expressing EGFP and were fixed at DIV 15 with $4 \%$ paraformaldehyde in PBS containing $4 \%$ sucrose for $2 \mathrm{~h}$ at $4{ }^{\circ} \mathrm{C}$. After washing with PBS, cultures were mounted with Hydromount (National diagnostics, Atlanta, GA, USA) and coverslipped. For analysis of hTau-dependent toxicity, slices were infected at DIV 12 with Sindbis virus expressing EGFP-coupled human 441 wt tau. At DIV 16, culture medium was harvested for cytotoxicity assays and lysates were prepared for western blot analyses.}

Drug treatments. NR2A-subunit-selective NMDAR antagonist PEAQX ([[[(1S)-1-(4-Bromophenyl)ethyl]amino](1,2,3,4-tetrahydro-2,3-dioxo-5-quinoxalinyl)methyl] phosphonic acid tetrasodium hydrate, $50 \mathrm{nM}$ ) was purchased from Sigma (Schnelldorf, Germany); NR2B-NMDAR antagonist Ifenprodil ((1S,2S)-threo-2(4-benzylpiperidino)-1-(4-hydroxyphenyl)-1-propanol hemitartrate, $3 \mu \mathrm{M}$ ), NMDAR antagonist MK801 ((5S,10R)-( + )-5-methyl-10,11-dihydro-5H-dibenzo[a,d]cyclohepten-5,10-imine maleate, $5 \mu \mathrm{M}), \mathrm{GABA}_{\mathrm{A}}$ antagonist bicuculline ([R-( $\left.\left.\mathrm{R}^{*}, \mathrm{~S}^{*}\right)\right]-6$ (5,6,7,8-tetrahydro-6-methyl-1,3-dioxolo[4,5-g]isoquinolin-5-yl)furo[3,4-e]-1,3-benzodioxol$8(6 \mathrm{H})$-one), $25 \mu \mathrm{m})$, potassium channel blocker 4-aminopyridine $(1 \mathrm{mM})$ and caspase-3 inhibitor Z-DEVD-FMK (benzyloxycarbonyl-Asp(OMe)-Glu(OMe)-ValAsp $(\mathrm{OMe})$-fluoromethylketone, $10 \mu \mathrm{M}$ ) were purchased from Tocris (Bristol, UK). We used two antibodies against $A \beta$, targeting either the $N$ terminus (6E10) or the $\mathrm{A} \beta$ mid-domain. The mid-domain antibody binds to both monomeric and aggregated $A \beta$ but not full-length APP. The control antibody was directed against bovine herpes virus. All antibodies were applied at concentrations of $1 \mu \mathrm{g} / \mathrm{ml}$

To determine the effect on dendritic spine density, cultures were treated for 7 days with the respective substance. For cell survival analysis, cultures were treated for 4 days.

Preparation of primary neuronal cultures. Neuronal cultures were prepared as described previously. ${ }^{60}$ On DIV 12, cultures were infected with Sindbis virus expressing EGFP or EGFP-hTau. At $16 \mathrm{~h}$ after infection, synaptic/ extrasynaptic activation protocols were performed followed by fixation $24 \mathrm{~h}$ after activation.

Immunblot analysis. On DIV 16, hippocampal slices were harvested in RIPA buffer ( $50 \mathrm{mM}$ Tris- $\mathrm{HCl}, 150 \mathrm{mM} \mathrm{NaCl}, 2 \mathrm{mM}$ EDTA, $1 \% \mathrm{NP}-40,0.5 \%$ deoxycholate and $0.1 \%$ SDS, pH 8.0) containing phosphatase inhibitor cocktails 1 and 2 (Sigma) and protease inhibitor cocktail (Roche, Basel, Switzerland) and centrifuged at $5000 \times \mathrm{g}$ for $10 \mathrm{~min}$ at $4{ }^{\circ} \mathrm{C}$. The supernatant was collected, frozen in liquid nitrogen and stored at $-80^{\circ} \mathrm{C}$.

Samples were resolved by $10-20 \%$ SDS-PAGE and transferred to nitrocellulose membranes (Millipore, Billerica, MA, USA). Immunoblotting was performed using primary antibodies anti-GFP (1:1000, Roche) to detect total GFP-coupled hTau, anti phospho-Tau AT8 (1:200, Thermo Fisher, Rockford, IL USA), Tau-5 (1:500, Neo Markers, Fremont, CA, USA), GSK-3 $\beta$ and phospho-GSK-3 $\beta$ (1:1000, Cell Signaling, Danvers, MA, USA), GAPDH (1:5000, Biodesign, Saco, ME, USA) and HRP-conjugated secondary antibody (1:2000, GE Healthcare, Glattbrugg, Switzerland). Immunoreactive bands were detected using the ECL Reagent (Thermo Fisher) or Supersignal Femto Maximum Sensitivity Substrate (Thermo, Rockford, IL, USA) according to the manufacturer's instructions and imaged with Fujifilm Las3000 (Fujifilm, Dielsdorf, Switzerland). It was verified by software tools that no pixels were saturated. Band intensities were quantified with ImageJ ( $\mathrm{NIH}$, Bethesda, MD, USA) corrected by background.

Assessment of cell death. To measure dead cell protease activity in slice cultures, culture medium was harvested at DIV 16, directly frozen in liquid nitrogen and stored at $-80^{\circ} \mathrm{C}$ for further analysis with CytoTox-Glo assay according to the manufacturer's recommendations. In the case of EGFP-tau overexpression, luminescence signals were normalized to EGFP fluorescence using microplate reader Synergy HT (BioTek, Bad Friedrichshall, Germany).

Cell viability and cytotoxicity were further determined using LIVE/DEAD Viability/ Cytotoxicity assay (Molecular Probes, Grand Island, NY, USA) according to the manufacturer's recommendations. EtHD-1-stained slices were imaged using Leica DMIRE2 fluorescence microscope (Leica, Heerbrugg, Switzerland) with excitation filters $470 / 40$ and 545/30, respectively. Images were acquired using identical microscope settings for all conditions devoid of saturation. Integrated fluorescence intensities relative to background fluorescence were determined by ImageJ program.

To analyze the effects of extrasynaptic activation in primary neuronal cultures, EGFP- or EGFP-hTau-expressing neurons were imaged using confocal microscopy. The ratio of non-degenerated infected neurons to total infected neurons was

Figure 3 Extrasynaptic NMDAR activation induces hTau-dependent toxicity in primary neuronal cultures and hippocampal slice cultures. (a) Representative confocal images of primary neurons expressing EGFP or EGFP-hTau after synaptic or extrasynaptic activation. (b) Confocal images of EGFP-hTau-expressing neurons after extrasynaptic activation and immunostaining against $\beta \mathrm{III}$ tubulin. Arrows mark non-infected neurons. (c) Quantification of hTau-dependent toxicity. Shown is the ratio of non-degenerated infected primary neurons (neurons without fragmented or beaded neurites or ballooned morphology) to total infected neurons. (d) Representative westem blot with phospho-ERK 1/2 (pERK) and ERK 1/2 antibodies of lysates from primary neurons after synaptic or extrasynaptic activation. (e) Cytotoxicity of hTau in wt hippocampal slice cultures after extrasynaptic activation measured by Cytotox-Glo assay. (f) Westem blot showing AT8 phosphorylation of hTau after extrasynaptic activation in slice cultures. (g) Representative dendritic segments from CA1 neurons of wt slice cultures after extrasynaptic activation. (h) Quantification of spine density in wt slices analyzed 1 day after extrasynaptic activation. eSyn, extrasynaptic; Syn, synaptic activation; veh, vehicle; values are shown as mean \pm S.E.M. with ${ }^{* \star} P<0.01$ and ${ }^{* \star} P<0.001$; Mann-Whitney-U-test; $n=10-13$ (c), $n=3$ (d); $n=8$ (e), $n=4$ (f); $n=10$ (h) scale bars: $50 \mu \mathrm{m}(\mathbf{a}, \mathbf{b}), 5 \mu \mathrm{m}(\mathrm{g})$ 
a

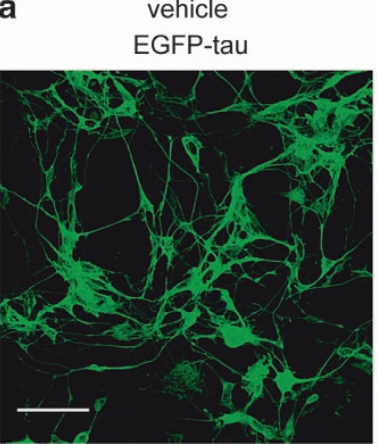

b
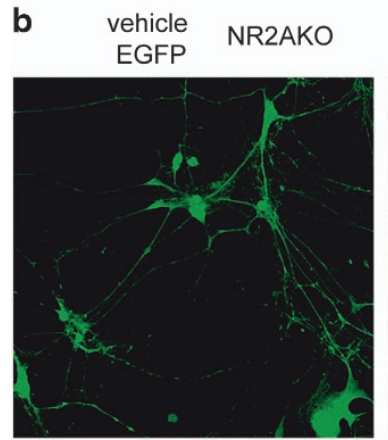

C
eSyn activation

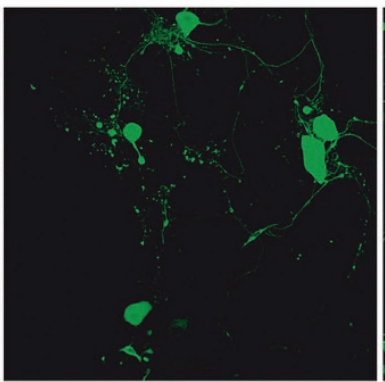

eSyn activation NR2AKO EGFP

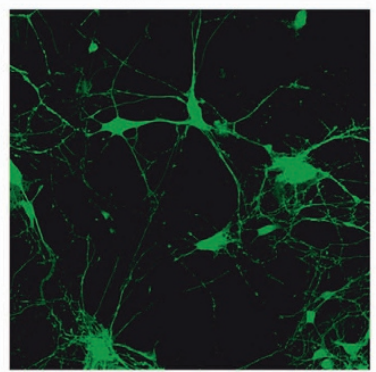

eSyn activation

BIII tubulin

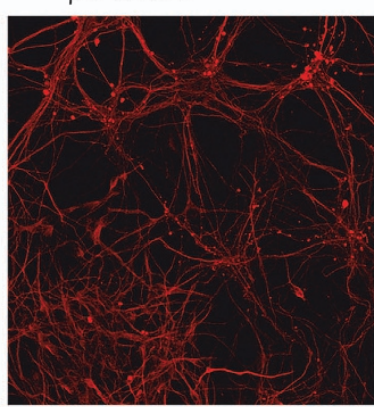

vehicle + Ifenprodil EGFP-hTau

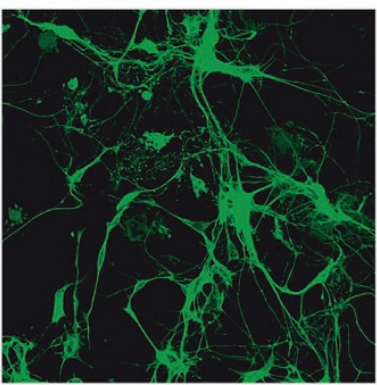

vehicle EGFP-hTau

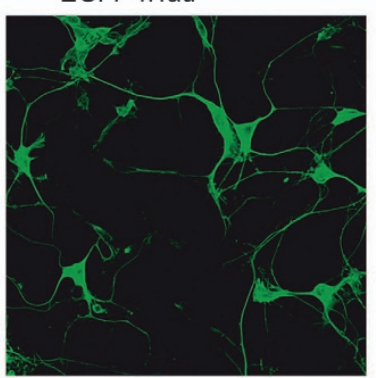

merge
eSyn activation + Ifenprodil EGFP-hTau

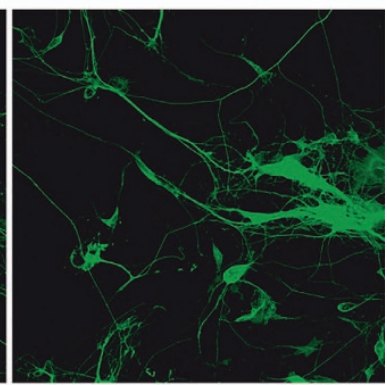

eSyn activation EGFP-hTau

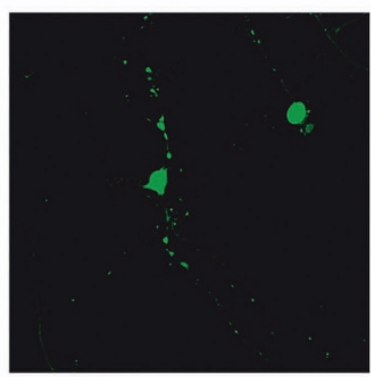

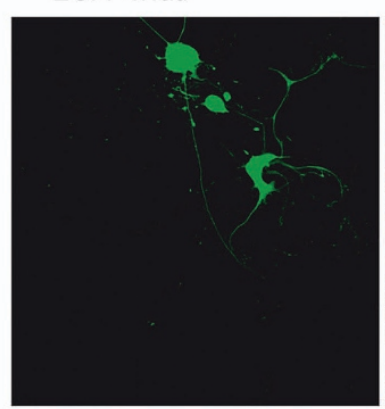
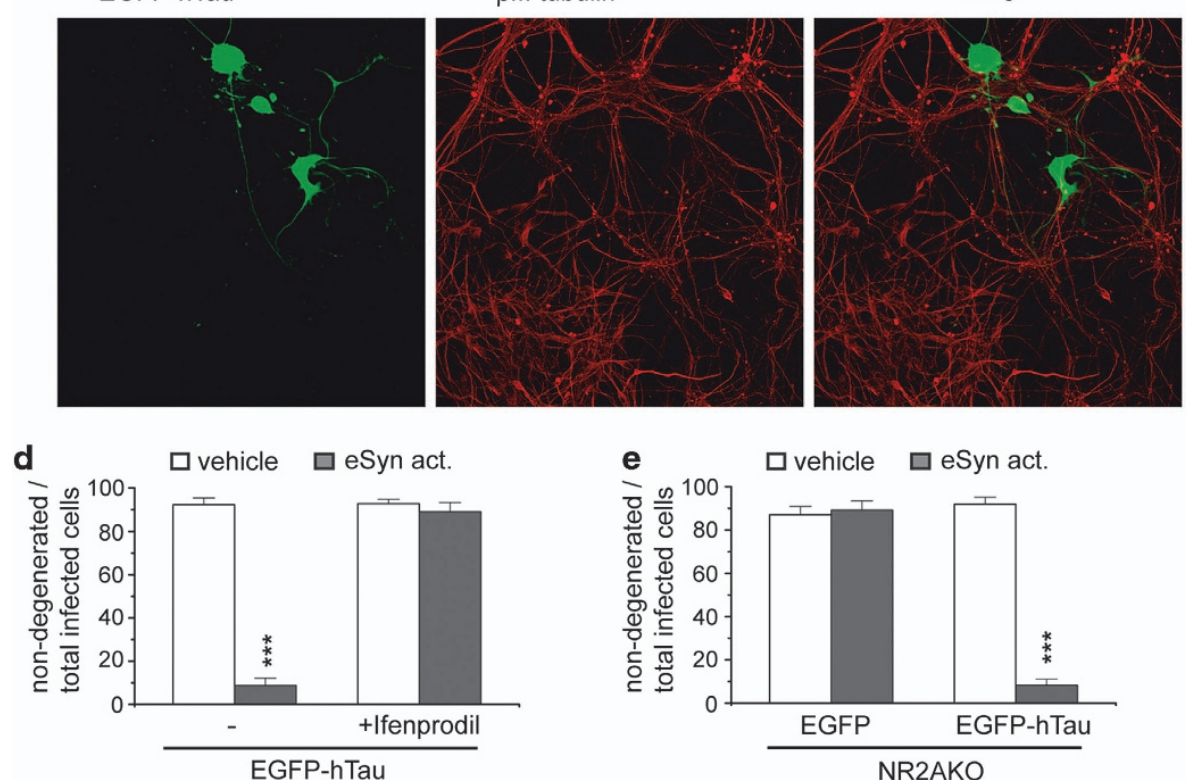

Figure 4 NR2B-containing NMDAR inhibition but not NR2A-containing NMDAR knockout abolishes hTau-dependent toxicity after activation of extrasynaptic NMDARs. (a) Representative confocal images of primary neurons expressing EGFP-hTau after extrasynaptic activation in the presence and absence of $3 \mu \mathrm{M}$ lfenprodil. (b) Representative confocal images of primary neurons from NR2AKO mice expressing EGFP-hTau after extrasynaptic activation. (c) Confocal images of EGFP-hTau-expressing primary neurons from NR2AKO mice after extrasynaptic activation and immunostaining against $\beta$ III tubulin. (d) Quantification of hTau-dependent toxicity in the presence and absence of Ifenprodil. Shown is the ratio of non-degenerated infected neurons (neurons without fragmented or beaded neurites or ballooned morphology) to total infected neurons. (e) Quantification of hTau-dependent toxicity in primary neurons of NR2AKO mice. eSyn act, activated eSyn NMDARs; values are shown as mean \pm S.E.M. with ${ }^{\star * \star} P<0.001$; Mann-Whitney-U-test; $n=10-14$; scale bar: $50 \mu \mathrm{m}$

determined by dividing the number of neurons without fragmented or beaded neurites or ballooned morphology by the total number of infected cells.

Dendritic spine analysis. For analysis of dendritic spine density, virus solution was diluted to achieve $1-10$ infected neurons per slice. This allowed imaging of single dendritic fragments. Analysis of dendritic spine density was performed using Leica SP2 CLSM equipped with $\times 63$ objective (NA: 1.2) and 488-nm Argon laser. Apical dendritic segments in CA1 and CA3 stratum radiatum were imaged with image size of $30 \times 30 \mu \mathrm{m}(512 \times 512$ pixel, voxel size: $0.05813 \times 0.05813 \times 0.25 \mu \mathrm{m})$. Image stacks were processed to maximum projections, and dendritic spine density was determined as spine counts per $\mu \mathrm{m}$ dendrite using ImageJ. 


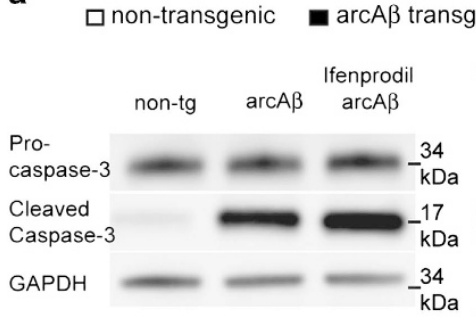

c

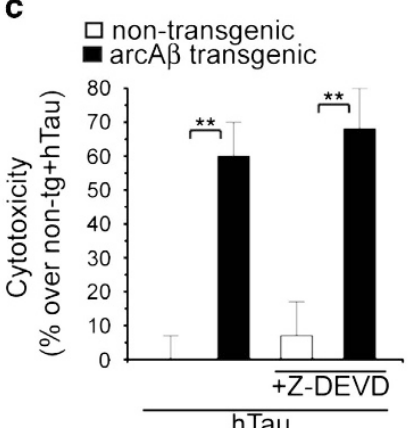

b

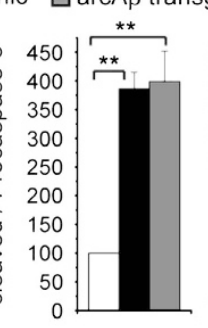

d

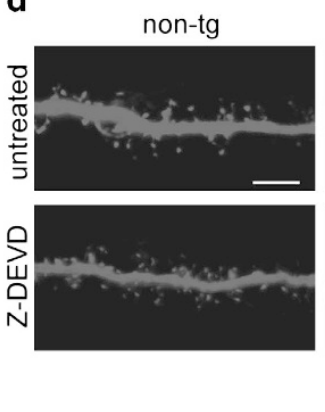

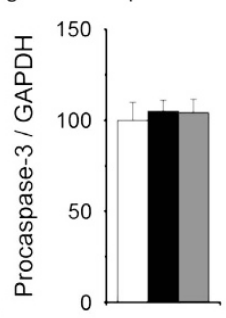

$\operatorname{arc} \mathrm{A} \beta \operatorname{tg}$

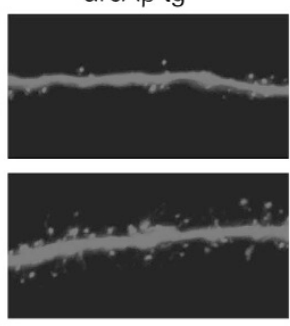

$\square$ NR2AKO $\square$ NR2AKO $x$ arcA $\beta$ transgenic
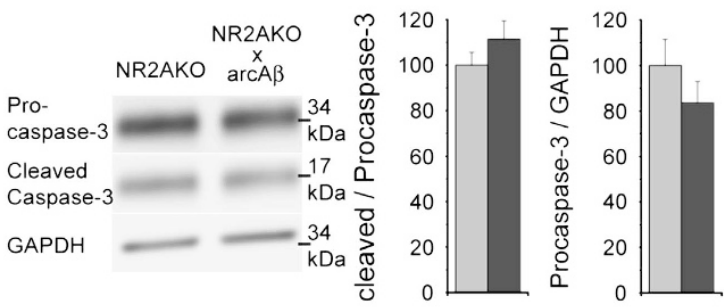

e

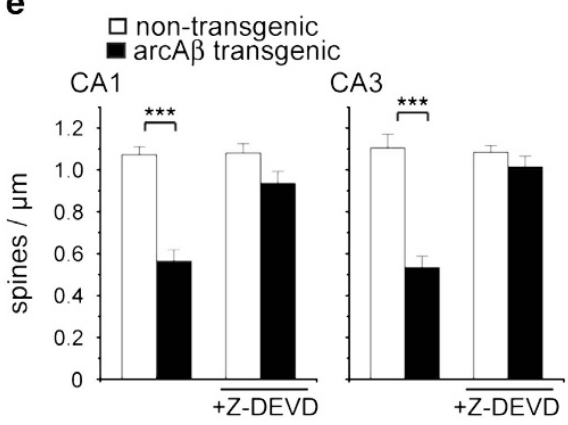

Figure 5 A $\beta$-induced caspase-3 activation causes dendritic spine loss but not hTau-dependent toxicity. (a) Western blot with antibodies against procaspase-3 and cleaved (activated) caspase-3 in slice cultures from $\operatorname{arc} A \beta \operatorname{tg}$ mice treated with $3 \mu \mathrm{M}$ Ifenprodil. (b) Western blot with antibodies against procaspase-3 and cleaved caspase-3 in cultured slices from NR2AKO and NR2AKO $\times \operatorname{arcA} \beta$ tg mice. (c) Cytotoxicity of hTau in $\operatorname{arcA} \beta$ tg and non-tg control slice cultures treated with $10 \mu \mathrm{M}$ Z-DEVD-FMK measured by Cytotox-Glo assay. (d) Representative confocal images of apical dendritic segments from CA1 neurons of $\operatorname{arcA} \beta \operatorname{tg}$ and non-tg slices treated with $10 \mu \mathrm{M}$ Z-DEVD-FMK. (e) Quantification of spine density after treatment with Z-DEVD-FMK. Z-DEVD, Z-DEVD-FMK; values are shown as mean \pm S.E.M. with ${ }^{* *} P<0.01$ and ${ }^{* \star *} P<0.001$; Mann-Whitney-U-test; $n=3-4(\mathbf{a}, \mathbf{b}), n=7-11$ (c, e); scale bar: $5 \mu \mathrm{m}$

Activation of synaptic/extrasynaptic NMDARs. For extrasynaptic activation, cultures were exposed to fresh neurobasal medium containing $1 \mathrm{mM} \mathrm{4}$ AP, $25 \mu \mathrm{M}$ bicuculline and $5 \mu \mathrm{M}$ MK801 for $5 \mathrm{~min}$ to activate and block synaptic NMDARs. Then, cultures were washed several times with neurobasal medium to remove unbound MK801, followed by incubation in Nb-N1 medium containing $50 \mu \mathrm{M}$ NMDA for $15 \mathrm{~min}$. Control cultures were treated with Nb-N1 medium containing water and DMSO vehicle.

To stimulate synaptic activation, cultures were exposed to neurobasal medium containing $1 \mathrm{mM} 4-\mathrm{AP}$ and $25 \mu \mathrm{M}$ bicuculline for $15 \mathrm{~min}$.

These protocols have been shown to selectively activate synaptic versus extrasynaptic NMDARs. ${ }^{12,29,30}$

To determine the effect of extrasynaptic NMDAR activation on dendritic spine density in slice cultures, slices were infected with EGFP-expressing virus on DIV 12, activation was carried out on DIV14 as described above and slices were fixed on DIV 15 for analysis of dendritic spine density.

Statistical analysis. Data are presented as mean \pm S.E.M. Statistical analysis was performed with Statview 5.0 (SAS Institute Inc., Cary, NC, USA) using Mann-Whitney-U-tests. Values of $P<0.05$ were considered statistically significant.

\section{Conflict of Interest}

JG is CSO of Neurimmune Holding AG, Wagistrasse 13, 8952 Schlieren, Switzerland.

Acknowledgements. CT was supported by the Deutsche Forschungsgemeinschaft (DFG, Ta762/1-1). SG and AT were supported by the Swiss National Science Foundation (SNF) grant 31003A 130148. ACS was supported by Novartis Stiftung. MCF was supported by Velux Stiftung. RB was supported by the Deutsche Forschungsgemeinschaft (DFG, BR1192/11-2). We thank Lawrence Rajendran for critical reading and valuable comments, and Masayoshi Mishina for kindly providing NR2A-NMDA receptor-knockout mice.
1. Rapoport M, Dawson HN, Binder LI, Vitek MP, Ferreira A. Tau is essential to beta -amyloidinduced neurotoxicity. Proc Natl Acad Sci USA 2002; 99: 6364-6369.

2. Tackenberg $C$, Brandt R. Divergent pathways mediate spine alterations and cell death induced by amyloid-beta, wild-type tau, and R406W tau. J Neurosci 2009; 29: 14439-14450.

3. Roberson E, Scearce-Levie K, Palop JJ, Yan F, Cheng IH, Wu T et al. Reducing endogenous tau ameliorates amyloid beta-induced deficits in an Alzheimer's disease mouse model. Science 2007; 31: 750-754.

4. Ittner LM, Ke YD, Delerue F, Bi M, Gladbach A, van Eersel J et al. Dendritic function of tau mediates amyloid-beta toxicity in Alzheimer's disease mouse models. Cell 2010; 142: 387-397.

5. Nussbaum JM, Schilling S, Cynis H, Silva A, Swanson E, Wangsanut T et al. Prion-like behaviour and tau-dependent cytotoxicity of pyroglutamylated amyloid-B. Nature 2012; 485: 651-655.

6. Lacor PN, Buniel MC, Furlow PW, Clemente AS, Velasco PT, Wood M et al. Abeta oligomer-induced aberrations in synapse composition, shape, and density provide a molecular basis for loss of connectivity in Alzheimer's disease. J Neurosci 2007; 27: 796-807.

7. Decker H, Jürgensen S, Adrover MF, Brito-Moreira J, Bomfim TR, Klein WL et al. N-methyl$\mathrm{D}$-aspartate receptors are required for synaptic targeting of Alzheimer's toxic amyloid- $\beta$ peptide oligomers. J Neurochem 2010; 115: 1520-1529.

8. De Felice FG, Velasco PT, Lambert MP, Viola K, Fernandez SJ, Ferreira ST et al. Abeta oligomers induce neuronal oxidative stress through an N-methyl-D-aspartate receptordependent mechanism that is blocked by the Alzheimer drug memantine. J Biol Chem 2007: 282: 11590-11601.

9. De Felice FG, Vieira MN, Bomfim TR, Decker H, Velasco PT, Lambert MP et al. Protection of synapses against Alzheimer's-linked toxins: insulin signaling prevents the pathogenic binding of Abeta oligomers. Proc Natl Acad Sci USA 2009; 106: 1971-1976.

10. Shankar GM, Bloodgood BL, Townsend M, Walsh DM, Selkoe DJ, Sabatini BL. Natural oligomers of the Alzheimer amyloid-beta protein induce reversible synapse loss by modulating an NMDA-type glutamate receptor-dependent signaling pathway. J Neurosci 2007; 27: 2866-2875.

11. Papouin T, Ladépêche L, Ruel J, Sacchi S, Labasque M, Hanini M et al. Synaptic and extrasynaptic NMDA receptors are gated by different endogenous coagonists. Cell 2012; 150: 633-646.

12. Hardingham GE, Fukunaga $Y$, Bading $H$. Extrasynaptic NMDARs oppose synaptic NMDARs by triggering CREB shut-off and cell death pathways. Nat Neurosci 2002; 5: 405-414. 
13. Hardingham GE, Bading H. Synaptic versus extrasynaptic NMDA receptor signalling: implications for neurodegenerative disorders. Nat Rev Neurosci 2010; 11: 682-696.

14. Steigerwald F, Schulz TW, Schenker LT, Kennedy MB, Seeburg PH, Köhr G. C-Terminal truncation of NR2A subunits impairs synaptic but not extrasynaptic localization of NMDA receptors. J Neurosci 2000; 20: 4573-4581.

15. Martel MA, Wyllie DJ, Hardingham GE. In developing hippocampal neurons, NR2Bcontaining $\mathrm{N}$-methyl-D-aspartate receptors (NMDARs) can mediate signaling to neuronal survival and synaptic potentiation, as well as neuronal death. Neuroscience 2009; 158: 334-343.

16. Xia $\mathrm{P}$, Chen HS, Zhang D, Lipton SA. Memantine preferentially blocks extrasynaptic over synaptic NMDA receptor currents in hippocampal autapses. J Neurosci2010; 30: 11246-11250.

17. Harris AZ, Pettit DL. Extrasynaptic and synaptic NMDA receptors form stable and uniform pools in rat hippocampal slices. J Physiol 2007; 584: 509-519.

18. Thomas CG, Miller AJ, Westbrook GL. Synaptic and extrasynaptic NMDA receptor NR2 subunits in cultured hippocampal neurons. J Neurophysiol 2006; 95: 1727-1734.

19. Li S, Jin M, Koeglsperger T, Shepardson NE, Shankar GM, Selkoe DJ. Soluble Aß oligomers inhibit long-term potentiation through a mechanism involving excessive activation of extrasynaptic NR2B-containing NMDA receptors. J Neurosci 2011; 31: 6627-6638.

20. Liu J, Chang L, Roselli F, Almeida OF, Gao X, Wang X et al. Amyloid-B induces caspasedependent loss of PSD-95 and synaptophysin through NMDA receptors. J Alzheimers Dis 2010; 22: 541-556

21. Texidó L, Martín-Satué M, Alberdi E, Solsona C, Matute C. Amyloid $\beta$ peptide oligomers directly activate NMDA receptors. Cell Calcium 2011; 49: 184-190.

22. Finder VH, Vodopivec I, Nitsch RM, Glockshuber R. The recombinant amyloid-beta peptide Abeta1-42 aggregates faster and is more neurotoxic than synthetic Abeta1-42. J Mol Biol 2010; 396: 9-18.

23. Shahani N, Subramaniam S, Wolf T, Tackenberg C, Brandt R. Tau aggregation and progressive neuronal degeneration in the absence of changes in spine density and morphology after targeted expression of Alzheimer's disease-relevant tau constructs in organotypic hippocampal slices. J Neurosci 2006; 31: 6103-6114.

24. Auberson $\mathrm{YP}$, Allgeier $\mathrm{H}$, Bischoff $\mathrm{S}$, Lingenhoehl $\mathrm{K}$, Moretti $\mathrm{R}$, Schmutz $M$. 5-Phosphonomethylquinoxalinediones as competitive NMDA receptor antagonists with a preference for the human $1 \mathrm{~A} / 2 \mathrm{~A}$, rather than $1 \mathrm{~A} / 2 \mathrm{~B}$ receptor composition. Bioorg Med Chem Lett 2002; 12: 1099-1102.

25. Feng B, Tse HW, Skifter DA, Morley R, Jane DE, Monaghan DT. Structure-activity analysis of a novel NR2C/NR2D-preferring NMDA receptor antagonist: 1-(phenanthrene-2carbonyl) piperazine-2,3-dicarboxylic acid. Br J Pharmacol 2004; 141: 508-516.

26. Berberich S, Punnakkal P, Jensen V, Pawlak V, Seeburg PH, Hvalby $\varnothing$ et al. Lack of NMDA receptor subtype selectivity for hippocampal long-term potentiation. J Neurosci 2005; 25: 6907-6910.

27. Li X, Lu F, Tian Q, Yang Y, Wang Q, Wang JZ. Activation of glycogen synthase kinase-3 induces Alzheimer-like tau hyperphosphorylation in rat hippocampus slices in culture. J Neural Transm 2006; 113: 93-102.

28. Peineau S, Taghibiglou C, Bradley C, Wong TP, Liu L, Lu J et al. LTP inhibits LTD in the hippocampus via regulation of GSK3beta. Neuron 2007; 53: 703-717.

29. Ivanov A, Pellegrino C, Rama S, Dumalska I, Salyha Y, Ben-Ari Y et al. Opposing role of synaptic and extrasynaptic NMDA receptors in regulation of the extracellular signalregulated kinases (ERK) activity in cultured rat hippocampal neurons. J Physiol 2006; 572: 789-798.

30. Hoey SE, Williams RJ, Perkinton MS. Synaptic NMDA receptor activation stimulates alphasecretase amyloid precursor protein processing and inhibits amyloid-beta production. J Neurosci 2009; 29: 4442-4460.

31. Dickson DW, Yen SH, Suzuki KI, Davies P, Garcia JH, Hirano A. Ballooned neurons in select neurodegenerative diseases contain phosphorylated neurofilament epitopes. Acta Neuropathol 1986; 71: 216-223.

32. D'Amelio M, Cavallucci V, Middei S, Marchetti C, Pacioni S, Ferri A et al. Caspase-3 triggers early synaptic dysfunction in a mouse model of Alzheimer's disease. Nat Neurosci 2011; 14: 69-76.

33. Jin M, Shepardson N, Yang T, Chen G, Walsh D, Selkoe DJ. Soluble amyloid beta-protein dimers isolated from Alzheimer cortex directly induce Tau hyperphosphorylation and neuritic degeneration. Proc Natl Acad Sci USA 2011; 108: 5819-5824.

34. Blurton-Jones M, Laferla FM. Pathways by which Abeta facilitates tau pathology. Curr Alzheimer Res 2006; 3: 437-448.

35. Gong CX, Singh TJ, Grundke-lqbal I, Iqbal K. Phosphoprotein phosphatase activities in Alzheimer disease brain. J Neurochem 1993; 61: 921-927.

36. Zempel H, Thies E, Mandelkow E, Mandelkow EM. Abeta oligomers cause localized $\mathrm{Ca}(2+)$ elevation, missorting of endogenous Tau into dendrites, Tau phosphorylation, and destruction of microtubules and spines. J Neurosci 2010; 30: 11938-11950.

37. Desikan RS, McEvoy LK, Thompson WK, Holland D, Roddey JC, Blennow K et al. Amyloid$B$ associated volume loss occurs only in the presence of phospho-tau. Ann Neurol 2011; 70: $657-661$.
38. Harada A, Oguchi K, Okabe S, Kuno J, Terada S, Ohshima T et al. Altered microtubule organization in small-calibre axons of mice lacking tau protein. Nature 1994; 269: 488-491.

39. Dawson HN, Ferreira A, Eyster MV, Ghoshal N, Binder LI, Vitek MP. Inhibition of neuronal maturation in primary hippocampal neurons from tau deficient mice. J Cell Sci 2001; 114: 1179-1187.

40. Tucker KL, Meyer M, Barde YA. Neurotrophins are required for nerve growth during development. Nat Neurosci 2001; 4: 29-37.

41. Muramatsu K, Hashimoto Y, Uemura T, Kunii M, Harada R, Sato T et al. Neuron-specific recombination by Cre recombinase inserted into the murine tau locus. Biochem Biophys Res Commun 2008; 370: 419-423.

42. Roberson ED, Halabisky B, Yoo JW, Yao J, Chin J, Yan F et al. Amyloid-B/Fyn-induced synaptic, network, and cognitive impairments depend on tau levels in multiple mouse models of Alzheimer's disease. J Neurosci 2011; 31: 700-711.

43. Vossel KA, Zhang K, Brodbeck J, Daub AC, Sharma P, Finkbeiner S et al. Tau reduction prevents Abeta-induced defects in axonal transport. Science 2010; 330: 198.

44. Gauthier-Kemper A, Weissmann C, Golovyashkina N, Sebö-Lemke Z, Drewes G, Gerke V et al. The frontotemporal dementia mutation R406W blocks tau's interaction with the membrane in an annexin A2-dependent manner. J Cell Biol 2011; 192: 647-661.

45. Steinhilb ML, Dias-Santagata D, Fulga T, Felch DL, Feany MB. Tau phosphorylation sites work in concert to promote neurotoxicity in vivo. Mol Biol Cell 2007; 18: 5060-5068.

46. Martel MA, Ryan TJ, Bell KF, Fowler JH, McMahon A, Al-Mubarak B et al. The subtype of GluN2 C-terminal domain determines the response to excitotoxic insults. Neuron 2012; 74 543-556.

47. Massey PV, Johnson BE, Moult PR, Auberson YP, Brown MW, Molnar E et al. Differential roles of NR2A and NR2B-containing NMDA receptors in cortical long-term potentiation and long-term depression. J Neurosci 2004; 24: 7821-7828.

48. Liu L, Wong TP, Pozza MF, Lingenhoehl K, Wang Y, Sheng M et al. Role of NMDA receptor subtypes in governing the direction of hippocampal synaptic plasticity. Science 2004; 304: 1021-1024.

49. Gambrill AC, Barria A. NMDA receptor subunit composition controls synaptogenesis and synapse stabilization. Proc Natl Acad Sci USA 2011; 108: 5855-5860.

50. Bordji K, Becerril-Ortega J, Nicole O, Buisson A. Activation of extrasynaptic, but not synaptic, NMDA receptors modifies amyloid precursor protein expression pattern and increases amyloid-3 production. J Neurosci 2010; 30: 15927-15942.

51. Wroge CM, Hogins J, Eisenman L, Mennerick S. Synaptic NMDA receptors mediate hypoxic excitotoxic death. J Neurosci 2012 6732-6742.

52. Li B, Chen N, Luo T, Otsu Y, Murphy TH, Raymond LA. Differential regulation of synaptic and extra-synaptic NMDA receptors. Nat Neurosci 2002; 5: 833-834.

53. Amadoro G, Ciotti MT, Costanzi M, Cestari V, Calissano P, Canu N. NMDA receptor mediates tau-induced neurotoxicity by calpain and ERK/MAPK activation. Proc Natl Acad Sci USA 2006; 103: 2892-2897.

54. Li Z, Jo J, Jia JM, Lo SC, Whitcomb DJ, Jiao S et al. Caspase-3 activation via mitochondria is required for long-term depression and AMPA receptor internalization. Cell 2010; 141: 859-871.

55. Jo J, Whitcomb DJ, Olsen KM, Kerrigan TL, Lo SC, Bru-Mercier G et al. Aß(1-42) inhibition of LTP is mediated by a signaling pathway involving caspase-3, Akt1 and GSK-3ß. Nat Neurosci 2011; 14: 545-547.

56. Wu HY, Hudry E, Hashimoto T, Kuchibhotla K, Rozkalne A, Fan Z et al. Amyloid beta induces the morphological neurodegenerative triad of spine loss, dendritic simplification, and neuritic dystrophies through calcineurin activation. J Neurosci 2010; 30: 2636-2649.

57. Wu HY, Hudry E, Hashimoto T, Uemura K, Fan ZY, Berezovska $O$ et al. Distinct dendritic spine and nuclear phases of calcineurin activation after exposure to amyloid- $\beta$ revealed by a novel fluorescence resonance energy transfer assay. J Neurosci 2012; 32: 5298-5309.

58. Kiyama Y, Manabe T, Sakimura K, Kawakami F, Mori H, Mishina M. Increased thresholds for long-term potentiation and contextual learning in mice lacking the NMDA-type glutamate receptor epsilon1 subunit. J Neurosci 1998; 18: 6704-6712.

59. Knobloch M, Konietzko U, Krebs DC, Nitsch RM. Intracellular Abeta and cognitive deficits precede beta-amyloid deposition in transgenic arcAbeta mice. Neurobiol Aging 2007; 28: 1297-1307.

60. Goodger Z, Rajendran L, Trutzel A, Kohli BM, Nitsch RM, Konietzko U. Nuclear signaling by the APP intracellular domain occurs predominantly through the amyloidogenic processing pathway. J Cell Sci 2009; 122: 3703-3714.

cc) (i) $(9) \Theta$ Cell Death and Disease is an open-access journal published by Nature Publishing Group. This work is licensed under a Creative Commons Attribution-NonCommercialNoDerivs 3.0 Unported License. To view a copy of this license, visit http://creativecommons.org/licenses/by-nc-nd/3.0/ 